\title{
O que é ser um acadêmico indígena de administração?
}

\author{
Renan Carlos KLICHOWSKI ${ }^{1}$ \\ MARCIO PASCOAL CASSANDRE ${ }^{1}$ \\ WAGNER ROBERTO DO AMARAL ${ }^{2}$
}

\author{
1 Universidade Estadual de Maringá (UEM) / Programa de Pós-graduação em Administração, Maringá - PR, Brasil \\ ${ }^{2}$ Universidade Estadual de Londrina (UEL) / Programa de Pós-Graduação em Política Social E SerVIÇo SOCIAL, LONDRINA - PR, BRASIL
}

\begin{abstract}
Resumo
Historicamente, a educação superior, em especial nos cursos de administração no Brasil, foi criada e aperfeiçoada pelas classes dominantes e seus interesses políticos e desenvolvimentistas. As iniciativas de reserva de vagas para indígenas estudarem nas universidades públicas brasileiras, como no caso das universidades estaduais do Paraná, a partir de 2001, passaram a ser uma novidade questionada por esses estudantes, por meio de barreiras levantadas na estrutura educacional não contemplativas do chamado pertencimento étnico-comunitário e acadêmico dos estudantes. O objetivo geral deste estudo é identificar e analisar quais as compreensões, expectativas e os dilemas presentes nos percursos formativos dos estudantes indígenas dos cursos de administração das universidades estaduais paranaenses. Em busca desse conhecimento, a história de vida, por meio da estratégia do testemunho, foi utilizada para compreender e analisar as experiências dos indígenas relativas aos seus percursos formativos. A pesquisa indicou pistas do que é ser um acadêmico de administração indígena no espaço acadêmico e étnicocomunitário, além de apontar anseios com relação ao mundo do trabalho. Teoricamente, o estudo trouxe uma perspectiva mais restrita ao duplo pertencimento, saindo de uma visão macro.
\end{abstract}

Palavras-chave: Estudante indígena. Universidade. Duplo pertencimento. Administração. Testemunho.

\section{What is it like to be an indigenous student of business administration?}

\begin{abstract}
Higher education programs in Brazil, especially those in business administration, have been historically established and designed by the upper classes for their political and developmentalist interests. The affirmative action of reserving places for indigenous people in the Brazilian public universities - such as in the case of the state universities of Paraná, from 2001 - became an important novelty. This policy, however, has been criticized by indigenous students given the existing barriers in the educational structure, which disregards dilemmas experienced by these students in their ethnic-community and academic spaces. The objective of this study is to identify and analyze the understandings, expectations, and dilemmas present in the educational paths of indigenous students enrolled in administration programs in the state universities of Paraná, Brazil. The testimony strategy was used to understand and analyze the educational experiences of indigenous students. The research indicated what it is like to be an indigenous higher education student of administration in the academic and ethnic-community spaces, besides pointing out anxieties regarding the world of work as indigenous administrators.
\end{abstract}

Keywords: Indigenous student. Indigenous peoples. Double Belonging. Administration. Testimony.

\section{¿Qué es ser un académico de administración indígena?}

\section{Resumen}

Históricamente, la educación superior, especialmente en la carrera de administración en Brasil, fue creada y perfeccionada por las clases dominantes, por sus intereses políticos y de desarrollo. Las iniciativas de reserva de vacantes para que indígenas estudien en las universidades públicas brasileñas, como en el caso de las universidades públicas del estado de Paraná a partir del año 2001, pasaron a ser una novedad importante pero cuestionada por los estudiantes indígenas, debido a las barreras planteadas en la estructura educativa brasileña que no contempla la denominada pertenencia étnico-comunitaria y académica de los estudiantes. El objetivo general de este estudio es identificar y analizar cuáles son las interpretaciones, expectativas y dilemas presentes en los itinerarios formativos de los estudiantes indígenas de los cursos de administración de las universidades públicas del estado de Paraná. En busca de ese conocimiento, se recurrió a la historia de vida por medio de la estrategia del testimonio- para comprender y analizar las experiencias de los indígenas con relación a su recorrido formativo. La investigación dio indicios de lo que es ser un estudiante indígena de administración en el espacio académico y étnico-comunitario, así como señaló anhelos con respecto al mundo del trabajo. Teóricamente, el estudio aportó una perspectiva más restringida a la doble pertenencia, al eximirse de una visión macro.

Palabras clave: Estudiante indígena. Universidad. Doble pertenencia. Administración. Testimonio. 


\section{INTRODUÇÃO}

Desde a história do contato com os europeus, a relação entre indígenas e Estado brasileiro manteve-se conflituosa, já que o último, tipicamente, representou os interesses da nobreza, da elite e da burguesia, seja no período colonial, no império, na república ou na ditadura (PACHECO DE OLIVEIRA e FREIRE, 2006; CARVALHO, 2013). Em tempos mais recentes, marcados pela democracia, no final da década de 1980, as lutas e conquistas alcançadas pelas populações indígenas podem ser evidenciadas na retomada e demarcação de seus territórios tradicionais, nas reivindicações por políticas públicas junto ao Estado, bem como nos embates por espaços por eles pouco ocupados, como as universidades, e na própria estrutura estatal (AMARAL, 2010; CARVALHO, 2013).

Uma das importantes conquistas foi o reconhecimento da Educação Escolar Indígena como modalidade específica da educação básica no Brasil, por meio da Lei de Diretrizes e Bases da Educação Nacional, de 1996 (CAPELO e TOMMASINO, 2004; PACHECO DE OLIVEIRA e FREIRE, 2006; AMARAL, 2010; AMARAL, RODRIGUES, e BILAR, 2014). A ampliação da oferta da educação básica específica, intercultural, bilíngue e comunitária para as populações indígenas possibilitou a simultânea e progressiva demanda de jovens indígenas para a educação superior nas últimas duas décadas no Brasil. Nesse contexto, no estado do Paraná, a Lei no 13.134/2001 foi reconhecida como outra conquista para os indígenas, que garantira vagas suplementares nas universidades estaduais paranaenses. Fato é que o pioneirismo dessas e de outras universidades públicas do Brasil legitima os conhecimentos acadêmicos produzidos pelos próprios indígenas nessas instituições de ensino, os quais podem se tornar uma significativa estratégia de afirmação cultural e política dos povos indígenas (AMARAL, 2010; AMARAL, RODRIGUES e BILAR, 2014).

Entretanto, ao realizar investigações sobre as trajetórias de acadêmicos indígenas, Amaral (2010) constata que seu ingresso na educação superior pública é necessariamente marcado por um "duplo pertencimento". Conforme conceitua o autor, essa conjuntura demanda, desses novos estudantes, uma articulação entre dois pertencimentos: o pertencimento étnico-comunitário e o pertencimento acadêmico. O pertencimento étnico-comunitário envolve os saberes, as regras próprias, os costumes, as tradições, a cultura e toda a gama de características específicas dos diferentes povos indígenas e de suas comunidades, às quais se vinculam os estudantes indígenas.

Já o pertencimento acadêmico requer do estudante uma correspondência às normas e regras da instituição de ensino superior, historicamente desenvolvidas por meio de lógicas não indígenas e capitalistas no Brasil. Ao mesmo tempo, tal pertencimento expõe o estudante a todas as possibilidades de perversidades, exclusões, conflitos, interculturalidades, conhecimentos e afirmação que possam encontrar nesse espaço (AMARAL, 2010). Dessa forma, os estudantes indígenas precisam lidar, na vivência acadêmica, com o duplo pertencimento, característica que influencia diretamente na constituição de novas categorias profissionais, incluindo indígenas nas categorias já existentes, como a de administradores, pedagogos e médicos (AMARAL, 2010; AMARAL, RODRIGUES e BILAR, 2014).

Buscando identificar como são abordados os estudos que refletem a temática de educação superior indígena e, em especial, a educação superior indígena em administração, no Brasil e no exterior, realizou-se uma revisão bibliográfica nas plataformas Spell e ProQuest, sem nenhuma restrição de recorte temporal. Na base de pesquisas nacional, foram encontrados 24 artigos, dos quais apenas 1 discute a educação superior indígena. Na base internacional, ProQuest, foram encontrados 23 artigos de oito países diferentes, dos quais 12 estão relacionados à educação superior indígena e outros 6 relacionados à educação intercultural. Constatou-se, assim, a existência de poucos estudos relacionados à educação superior indígena (nessas bases de dados), conforme já indicavam estudos de alguns autores sobre o assunto (AMARAL, 2010; AMARAL, RODRIGUES e BILAR, 2014; CASSANDRE, AMARAL e SILVA, 2016; ANGNES, FREITAS, KLOZOVSKI et al., 2017; AMARAL, FRAGA e RODRIGUES, 2016).

Segundo dados fornecidos pela Comissão Universidade para os Índios do Paraná, dos 163 indígenas matriculados nas universidades estaduais paranaenses no início do ano letivo de 2017, 7 estavam matriculados no curso de administração, mas, durante o mesmo ano, 3 deles desistiram. Assim, são 4 os estudantes indígenas que permanecem matriculados em administração no referido ano.

Tendo em vista o contexto de ingresso e permanência de estudantes indígenas nas universidades estaduais paranaenses, este artigo tem como objetivo identificar e analisar quais as compreensões, expectativas e os dilemas presentes nos percursos formativos dos estudantes indígenas dos cursos de administração das universidades estaduais paranaenses. 
Destaca-se que as iniciativas realizadas pelas universidades brasileiras e, de forma diferenciada, pelo governo do estado do Paraná, colocadas em prática nos anos 2000, e em 2012 nas instituições de ensino superior (IES) federais, são recentes, ao se considerar os 518 anos de contato entre as sociedades indígenas e as sociedades não indígenas no território brasileiro. Logo, o surgimento de profissionais indígenas e, em especial, de administradores indígenas é uma novidade que precisa ser referenciada para que se abra um campo crítico de avaliações e proposições para as instituições formativas, para as organizações contratantes e para as sociedades indígenas e não indígenas. Nesse sentido, o presente estudo é relevante por ser uma fonte de referência para ampliação de discussões na área de administração, inovadora para os estudos organizacionais, principalmente no que se refere às discussões sobre diversidade nas organizações.

\section{PERCURSO METODOLÓGICO}

Em um primeiro momento da pesquisa, foram feitos levantamentos de dados secundários em publicações científicas, artigos, materiais impressos, livros, arquivos públicos, arquivos particulares, fontes estatísticas, entre outras. Utilizou-se, também, de informações disponíveis no Censo demográfico de 2010, no sítio online da Fundação Nacional do Índio (FUNAI) ${ }^{1}$, e em Pacheco de Oliveira e Freire (2006). Os dados e informações foram reproduzidos nesta pesquisa também de forma secundária, sem novos tratamentos estatísticos.

Posteriormente, após o levantamento de dados bibliográficos, nas bases Spell (nacional) e ProQuest (internacional), como uma forma de escutar a percepção dos estudantes, com a intenção de empregar uma perspectiva epistemológica que represente os sujeitos da pesquisa e "superar a invisibilidade pública dos povos indígenas" (AMARAL, 2010, p. 153), utilizou-se o testemunho como estratégia para abordagem da história de vida, técnica qualitativa que permitiu identificar a experiência pessoal do sujeito - no caso, o estudante indígena (BERNAL, BURCIAGA e CARMONA, 2012).

Nessa fase de contato com os estudantes indígenas, foi elaborado um roteiro semiestruturado para auxiliar o entrevistador, servindo como uma ferramenta acessória para o desenvolvimento da escuta dos testemunhos. Esse roteiro foi dividido em três partes: a) identificação dos entrevistados; b) trajetórias na universidade; e c) trajetórias e expectativas sobre o mundo do trabalho.

Nesta pesquisa, todos os estudantes indígenas matriculados nos cursos de administração das universidades estaduais paranaenses aceitaram, após contato prévio, contribuir com seus testemunhos gravados em áudio, transcritos e organizados em texto escrito. A coleta dos testemunhos ocorreu de forma individual, sem a participação de terceiros, nem interrupções durante a conversa. A gravação em áudio serviu para que os indivíduos pudessem se sentir mais à vontade, com o mínimo de formalidade e sem intervenção por parte do entrevistador, como forma de manter distanciamento. Assim, as histórias eram contadas pelos estudantes de forma pessoal e livre.

Ao final de cada abordagem testemunhal, poucas horas depois, o entrevistador efetuou a transcrição literal de cada testemunho. No dia seguinte, os textos foram enviados aos estudantes indígenas por meio eletrônico (WhatsApp e e-mail) para que confirmassem o que haviam dito. Em todos os casos, o retorno dos estudantes aconteceu no mesmo dia, apenas com correções relacionadas a nomes pessoais e de lugares. Para manter o sigilo quanto à identidade dos participantes, seus nomes foram substituídos por outros de origem indígena: Yara, Niara, Ubirajara e Raoni.

Neste artigo, apresenta-se uma síntese dos testemunhos, evidenciando percepções e indicações sobre a temática, combinados a elementos expostos ao longo deste artigo, explicando o que pode ser entendido nas três temáticas que foram abordadas. Os testemunhos não foram reproduzidos nesta publicação devido à questão de espaço e quantidade de palavras, mas, de qualquer forma, foram trazidos trechos essenciais para o entendimento da síntese.

A partir do entendimento e do esclarecimento do percurso metodológico percorrido neste trabalho de pesquisa, a seguir, destaca-se um espaço do artigo para o entendimento empírico-teórico relativo ao duplo pertencimento.

${ }_{1}^{1}$ Dados consultados no endereço online da Fundação Nacional do Índio (FUNAI), disponível em: <http://www.funai.gov.br/index.php/indios-no-brasil/quemsao>. Acesso em junho/2017. 


\section{O duplo pertencimento do ponto de vista macro}

O ingresso de indígenas nas universidades estaduais do Paraná, segundo Amaral (2010), provoca, no estudante indígena, a vivência de um processo árduo. Nesse processo, esses estudantes precisam lidar com valores presentes nas sociedades indígenas e nas sociedades não indígenas, esta última fundamentalmente urbana. Simultaneamente, os estudantes indígenas vivenciam o duplo pertencimento, processo novo para as universidades, para as comunidades originárias e para as sociedades urbanas, principalmente para esses sujeitos.

Ao analisar os percursos de estudantes indígenas na educação superior pública no Paraná, Amaral (2010) reflete o fenômeno do duplo pertencimento, evidenciando e defendendo que a permanência de indígenas nas universidades estaduais do Paraná (a partir do Vestibular dos Povos Indígenas) só é possível quando esses sujeitos conseguem "constituir e manter a sua identidade como estudante indígena universitário, demandando deste sujeito a sustentação simultânea de sua pertença acadêmica e étnico-comunitária" (AMARAL, 2010, p. 510).

Essa situação, segundo Amaral (2010), Angnes, Freitas, Klozovski et al. (2017) e Amaral, Fraga, Rodrigues (2016), é resultado de lutas reivindicatórias iniciadas por movimentos e organizações indígenas que buscavam a institucionalização de escolas indígenas com a garantia de que a educação básica promovesse os "princípios do bilinguismo, especificidade e da interculturalidade" (como ficou previsto e normatizado em lei). A educação superior passou a ser fortemente pautada pelas organizações indígenas e indigenistas por ser uma alternativa e estratégia para formação e habilitação de professores indígenas para atuarem nas escolas criadas dentro das terras indígenas (AMARAL, 2010, p. 66).

Fato é que o ineditismo assumido pelas universidades estaduais do Paraná, e por outras universidades públicas do Brasil, na mesma década, passa a expressar que os conhecimentos acadêmicos produzidos pelos próprios indígenas nas universidades públicas tornaram-se uma forte estratégia de afirmação cultural e política destes povos (AMARAL, 2010). Entretanto, para Amaral (2010), Angnes, Freitas, Klozovski et al. (2017) e Amaral, Fraga e Rodrigues (2016), o ingresso e a permanência dos indígenas nas universidades e nos espaços urbanos pouco frequentados cotidianamente por eles evidenciam o desafio do intercâmbio de diferentes concepções, experiências e perspectivas, o que lhes provoca reflexões quanto as suas identidades étnicas.

Ao sintetizar a análise conceitual refletida por Amaral (2010), identificam-se três categorias significativas que orientam a sua tese: 1) o pertencimento acadêmico, caraterizado para além de uma matrícula formal, vinculada aos processos vividos pelos indígenas na sua dimensão acadêmica, tendo em vista sua permanência na universidade como estudante; 2) o pertencimento étnico-comunitário, correspondente às suas origens socioculturais, aos aspectos de sua identidade étnica, de sua vinculação comunitária, entre outros; e 3) o duplo pertencimento, que reúne e manifesta as associações e as tensões das duas pertenças.

Um grupo étnico não é um grupo fechado e estático; o pertencimento étnico, a identidade e a cultura são dinâmicos e negociáveis, de acordo com Barth (1998). O conceito de grupo étnico pode ser entendido como uma organização social "que possui um grupo de membros que se identifica e é identificado por outros como se constituísse uma categoria diferenciável de outras categorias do mesmo tipo" (BARTH, 1998, p. 190-193).

Quando grupos diferentes entram em contato, ocorrem friç̧ões, manifestações, mudanças culturais, em que são expostas as fronteiras étnicas. Segundo Barth (1998), entende-se como fronteira étnica a manifestação destacada no relacionamento de diferentes pessoas e grupos, explicitando persistências e mudanças em regras e traços culturais expressos pela adoção de uma identidade, exclusão ou inclusão de um membro a um grupo.

Em outras palavras, uma fronteira étnica é o contraste de uma etnia com outra, como forma de defender um grupo ou manifestar inclusão e mudança. Barth (1998) acrescenta que, seja de forma consciente ou não, um indivíduo atua na dinâmica de sua identidade étnica ou etnicidade do seu grupo. Grande parte de uma identidade étnica apreendida é inconsciente e incorporada desde o nascimento do sujeito, constituída de forma relacional, estando sempre em construção.

Cardoso de Oliveira $(1964,1976,2006)$ apresenta questões importantes quando se trata de reflexões em relação à identidade, principalmente em relação a questões de conflitos étnico-raciais. Destaca-se o conceito de "fricção interétnica", que é momento de conflito entre identidades de diferentes etnias e culturas, ou quando são manifestadas as fronteiras étnicas. Por exemplo, quando grupos ou pessoas de diferentes culturas manifestam suas características identitárias frente a outros grupos, evidencia-se uma fronteira étnica, e o conflito nessas relações é, para o autor, uma fricção interétnica. 0 ingresso de estudantes indígenas em universidades públicas pode evidenciar diferentes momentos de fricção, seja na relação entre estudantes, professores, ou mesmo entre indígenas de diferentes etnias. 
Outra importante reflexão de Cardoso de Oliveira $(1964,1976)$ é relativa aos conceitos de assimilação e aculturação. O primeiro deles é definido como o processo social no qual diferentes indivíduos ou grupos aceitam e adquirem padrões comportamentais, tradições, sentimentos e atitudes da outra parte. Pode-se dizer que é um ajustamento interno e um indício de integração sociocultural quando da reunião de grupos diferentes. Já o conceito de aculturação expressa a sobreposição de uma cultura à outra, quando uma das culturas deixa de existir. No caso dos estudantes indígenas, a convivência com diferentes cosmologias dentro da universidade poderá trazer novas ressignificações de comportamentos ou de compreensões para esses sujeitos.

Cardoso de Oliveira $(1964,2006)$ também destaca o conceito de etnocentrismo, que pode ser compreendido como atitude emocional que sustenta um grupo, uma raça, etnia ou sociedade a que uma pessoa pertence, que supostamente seriam superiores a outros grupos raciais, sociais, étnicos ou culturais. Associa-se ao desprezo pelo estrangeiro ou forasteiro, bem como por seus costumes. Uma ferramenta que pode servir ao preconceito é o estigma, uma forma de expor uma característica negativa pejorativamente, estereotipando e excluindo aquele que é etnicamente "diferente" (CARDOSO DE OLIVEIRA, 2006). Por exemplo, estudantes indígenas podem ser desprezados por estudantes não indígenas devido a sua origem, ou estes últimos podem vir a duvidar dos primeiros quanto às capacidades daqueles, principalmente porque as instituições de ensino são formatadas originalmente para não indígenas.

A estrutura das universidades está cercada por interesses das elites dominantes e não foi idealizada para indígenas (CUNHA, 1980, 2007; MINOGUE, 1981; CAMACHO, 2005; XERRI, 2012). Segundo Larkin (2011), o positivismo neoliberal está impregnado na cultura educacional ocidental, sendo uma epistemologia racista, que reproduz conhecimento e ridiculariza outras formas de conhecimento, como o indígena.

Nesse sentido, Bodkin-Andrews, O’Rourke, Dillon et al. (2012) apontam para a necessidade de reorganização das instituições de ensino, que precisam dar condições e acompanhar os estudantes indígenas que ingressam na escola-universidade, ação necessária para reduzir números relacionados à evasão e ao desengajamento. Segundo Estácio e Almeida (2016), no estudo sobre a experiência do estado do Amazonas (Brasil) em relação à reserva de vagas para povos indígenas, não basta criar vagas para indígenas estudarem em universidades, é necessário, também, um acompanhamento institucional a partir desse ingresso, para que sejam amenizadas as dificuldades oriundas de diferenças étnico-culturais.

Bouton-Lewis, Wilss e Lewis (2001) apresentam um estudo que demonstra que, a partir do segundo ano na universidade, os estudantes indígenas tomam maior consciência da aprendizagem. Isso evidencia, para as universidades, que é necessário oportunizar um tempo de adaptação para estudantes indígenas ingressantes, medida que pode ajudar a evitar o desengajamento e a evasão. Ainda em relação às alternativas para amenizar as dificuldades e diminuir as desistências, Usher, Lindsay e Mackay (2005) e Usher, Miller, Turale et al. (2005) apresentam a alternativa de levar a universidade para as proximidades das aldeias, ideia que reduz dificuldades relacionadas ao deslocamento e a gastos financeiros, e evita o distanciamento da família e da comunidade.

Constata-se que o ingresso de indígenas na educação superior e em universidades públicas não é uma preocupação exclusiva do estado do Paraná e do Brasil. Acrescenta-se que, fora do Brasil, esse fenômeno também se evidencia, por exemplo, na Nova Zelândia. Rakena, Airini e Brown (2016) reconhecem a presença de indígenas na educação superior neozelandesa como atravessada por dois mundos, de uma cosmovisão hegemônica ocidental e a de um próprio ethos indígena.

Nesse sentido, foi possível constatar que a emergência de indígenas nas universidades é algo complexo. As pesquisas de Amaral (2010) e de outros autores (NOVAK, 2007; PAULINO, 2008; CASSANDRE, AMARAL e SILVA, 2016; ANGNES, FREITAS, KLOZOVSKI et al., 2017; AMARAL, FRAGA, e RODRIGUES, 2016) demonstraram o quão complexo pode ser o percurso educacional indígena dentro das universidades. As reflexões de Bajada e Trayler (2014) incluem a formação de administradores como uma emergência para a vivência dos povos indígenas, como apresentado também no estudo de Cassandre, Amaral e Silva (2016). Faz-se necessário destacar aqui que, a partir dos processos indenizatórios de empreendimentos hidroelétricos, ferrorrodoviários, entre outros, as comunidades indígenas passam a desenvolver projetos produtivos próprios, necessitando de pessoas capacitadas para a gestão desses negócios, pertencendo, estas, às mesmas comunidades. Assim, a academia precisa dar condições para os indígenas se formarem como profissionais administradores, de forma coerente com os saberes, cosmologias e expectativas dos grupos étnicos aos quais pertencem. Amaral (2010) denomina como "novo circuito de trabalho indígena intra e (ou) interaldeias" o surgimento de profissionais indígenas diplomados e formados na educação superior, uma expectativa dos estudantes indígenas que ingressaram em universidades, bem como de suas famílias e suas comunidades. 


\section{Os testemunhos: o duplo pertencimento no curso de administração}

Os testemunhos apresentados sinalizaram perspectivas em três momentos, a partir dos pontos indicados no roteiro elaborado para a pesquisa: identificação; trajetória nas universidades; e trajetórias e expectativas sobre o mundo do trabalho.

\section{Identificação}

No primeiro momento, o de identificação, a existência do duplo pertencimento acadêmico e étnico-comunitário foi percebida e confirmada no relato testemunhal dos estudantes indígenas, que informaram relacionamentos cotidianos frequentes com familiares e com o povo das terras indígenas (morando ou não em uma aldeia), simultaneamente à vivência universitária. $\mathrm{O}$ estudante indígena Raoni, por exemplo, não morava na aldeia no período da realização da entrevista, mas nasceu, viveu por muito tempo e mantém laços de convivência com sua comunidade, principalmente com seus primos, tios e parentes que ainda moram por lá, e com amigos, sendo evidenciado quando disse ir à terra indígena para jogar futebol e conversar com seus parentes indígenas.

A saída de Raoni da moradia em terras indígenas não o exclui do seu grupo étnico de pertencimento. Como citado, Barth (1998) já afirmava que um grupo étnico não é estático, e que a cultura, a identidade e o pertencimento são dinâmicos e negociáveis. Conceitualmente, um grupo étnico é visto como uma organização social com membros que se identificam e são identificados por outrem como uma categoria, como membro que pertence a ela (BARTH, 1998; CARDOSO DE OLIVEIRA, 2006). Nesse sentido, Raoni afirma sua identidade e seu pertencimento indígena, independentemente de sua residência não ser em terra indígena. No seu relato, podemos observar que, assim como ele, outros jovens indígenas saíram das terras indígenas devido à busca por melhores condições de trabalho, para estudar e, algumas vezes, por conflitos internos.

Notou-se que os pertencimentos de cada um dos entrevistados podem ter níveis variados quanto às características de seu pertencimento étnico-comunitário frente ao pertencimento acadêmico, como no caso de Raoni comparado ao de Yara, que vive em uma aldeia que não tem energia elétrica. Nesse sentido, o impacto da dupla pertença ou do novo pertencimento acadêmico para cada indígena pode ter graus de dificuldade e de adaptação muito diferentes, o que afeta diretamente uma generalização que possa considerar o estudante indígena como um grupo homogêneo. Assim, o "árduo" processo de convivência dos estudantes indígenas na universidade, mencionado por Amaral (2010), pode ser visto em medidas diferentes.

Além disso, deve-se levar em consideração o ambiente de cada universidade. Cada uma das universidades estaduais do Paraná possui uma história, um porte, características locais e regionais, uma estrutura administrativa, políticas de acolhimento e de permanência, políticas de assistência estudantil e características institucionais específicas. É notório, no relato de Yara, o sentimento de que tem pouco apoio na universidade, pois, segundo ela, "a instituição não me dá nenhuma ajuda". Ubirajara ainda é mais específico, informando que, vez ou outra, aparece alguém da CUIA para fazer reunião, mas não tem acompanhamento. Por outro lado, Niara e Raoni relatam que são acompanhados de perto pela instituição de ensino, desde quando chegaram. As relações podem ser muito diferentes, também se for levado em consideração o número de indígenas em cada instituição e a distância do território indígena com a universidade. Tudo isso pode impactar diretamente em possíveis preconceitos e fragilidades no pertencimento acadêmico do estudante indígena.

Os testemunhos mostraram que existem diferenças entre compreensões indígenas e não indígenas para questões relacionadas ao dia a dia, como relacionamentos hierárquicos e conhecimentos. Além disso, todos os entrevistados declararam que o conhecimento indígena e o conhecimento ensinado na universidade não se equivalem, sendo que Yara e Raoni indicaram possíveis e importantes conexões, e Niara e Ubirajara sinalizaram sua total dicotomia. Também foi possível constatar o quão diversas são as estruturas nas terras indígenas e os indígenas que pertencem a elas. No grupo estudado, todos tinham idade inferior a 30 anos; alguns eram casados e tinham filhos, outros não; outros eram solteiros; alguns falavam a língua indígena e outros não - mas todos se identificaram como indígenas.

\section{Trajetória nas universidades}

No segundo momento, sobre as trajetórias nas universidades, identificamos que todos os entrevistados citaram em suas expectativas iniciais o interesse de adquirir conhecimentos, mas a opção pelo curso de administração foi manifestada de forma pessoal, ou seja, cada um apresentou um motivo, tais como: apenas vontade de aprender, de obter um "bom trabalho" (como relatou Niara) ou por ser a opção de curso cujo acesso é mais fácil. 
Nesse momento, ficou evidente o pertencimento acadêmico ao curso de administração. Relativos a esse pertencimento, quando o assunto eram as dificuldades vivenciadas durante a permanência na universidade, o transporte e a distância entre local de estudo e moradia apareceram no relato de quase todos os testemunhantes. Percebeu-se, também, problemas com comunicação eletrônica e virtual, uma vez que alguns deles não possuem recursos estruturais em suas casas, como internet ou mesmo energia elétrica, o que pode limitar, de alguma forma, sua participação em atividades extracurriculares nas quais existe a necessidade de pesquisas on-line, nas situações em que professores enviam materiais de estudo pela internet ou mesmo de comunicação entre colegas da turma. Mesmo assim, todos eles continuam suas trajetórias na graduação em administração.

Os estudantes indígenas manifestaram que existem incentivos para continuar estudando, sendo de familiares e, em alguns casos, da própria universidade. Yara é específica ao dizer que "só minha mãe que me incentiva, a universidade não". Já Ubirajara diz buscar motivação na expectativa de conquistar uma vaga de trabalho em um concurso público quando estiver formado.

O relacionamento com colegas de universidade (indígenas e não indígenas), professores e comunidades indígenas foi outro assunto dos relatos testemunhais. Com exceção de Yara, todos eles disseram que o relacionamento é muito bom, seja com os membros da universidade (estudantes, professores, coordenação), seja com indígenas de suas aldeias (lideranças, família, comunidade). Yara disse ser muito fechada, e entende que, talvez por isso, as pessoas da universidade não falem muito com ela, tendo conseguido criar amizades com alguns e ter melhor relação apenas com uma professora.

No relato de Yara, um notório preconceito foi manifestado. Em sala de aula, quando um professor resolve dar atividades em grupo,

a gente percebe que, às vezes, evitam a gente, quando a gente vai fazer trabalho. Esse ano mesmo, no terceiro ano, a professora fez para a gente não se escolher, a professora fez assim, número 1, número 2, número 3, daí fui com um piá [menino], e o piá falou assim: professora, não dá para trocar? Essas coisas que acontecem.

Apesar de ter bons relacionamentos com não indígenas e não ter problemas semelhantes aos de Yara, Ubirajara confirmou existir esse tipo problema: "tem uns que reclamam que, dentro da sala, o professor pegar mais no pé, os alunos também na hora de formar grupo, na hora de fazer trabalho. Comigo não, graças a Deus".

Nesse ponto dos testemunhos, Yara e Ubirajara manifestaram situações que podem ser alarmantes: episódios de preconceito. Cardoso de Oliveira $(1964,1976,2006)$ pondera que o estigma e o etnocentrismo são mecanismos que evidenciam e afirmam o preconceito, sendo um estereótipo de exclusão daquele que é "diferente". Yara, de forma mais expressa, mostra que sente na pele os momentos em que não é identificada e incluída nas relações cotidianas com seus colegas de turma dentro da universidade.

Como mencionado na introdução deste artigo, o curso de administração foi configurado historicamente no contexto capitalista, com origens e influências vinculadas às teorias norte-americanas. Logo, o interesse de indígenas por esse curso pode evidenciar conflitos ideológicos. Por outro lado, pesquisas científicas que envolvam as intencionalidades, necessidades, expectativas, cosmologias indígenas podem ser notáveis alternativas para superar o paradigma das teorias elitistas da administração. Raoni, em seu testemunho, afirmou perceber que existe espaço na universidade para que estudantes indígenas desenvolvam pesquisas relacionadas aos interesses de suas comunidades. Ele sente que isso depende de um interesse pessoal e coletivo e que, desde que ingressou na universidade, no entanto, viu poucas pesquisas relacionadas de alguma forma aos temas afetos aos povos indígenas. Niara, da mesma universidade, relatou saber de um estudo; já Yara e Ubirajara nunca viram algo nesse sentido.

Os testemunhos revelam a percepção de que as universidades pouco se preocupam em promover estudos que atendam aos anseios dos povos indígenas, o que pode, de alguma forma, desmotivar ou não pautar as necessidades desses grupos originários. Por outro lado, a existência de vagas suplementares para indígenas, como a que se refere ao caso do estado do Paraná, ainda possibilita uma situação favorável em que os próprios acadêmicos indígenas passam a empreender seus percursos nas instituições de ensino superior. Em contraponto, como apresentado por diversos dos autores (AMARAL, 2010; AMARAL, FRAGA e RODRIGUES, 2016; ANGNES, FREITAS, KLOZOVSKI et al., 2017; BODKIN-ANDREWS, O'ROURKE, DILLON et al. 2012; ESTÁCIO E ALMEIDA, 2016), não basta a reserva de vagas para ingresso de indígenas, é necessário também garantir uma política de permanência adequada, que possibilite o acompanhamento pedagógico, a assistência estudantil, a produção de conhecimentos por meio da pesquisa e da extensão por esses sujeitos em constante relação com suas comunidades de pertencimento. É fundamental que a presença dos estudantes indígenas contribua para interculturalizar a educação superior e a universidade (MATO, 2018). 
Com relação à autoavaliação do desempenho acadêmico, todos os estudantes indígenas testemunhantes assumiram alguma dificuldade. A demanda de trabalho surgiu como um fator limitador para o desempenho escolar, por ocupar muito tempo em suas rotinas diárias e deixar pouco espaço para dedicação aos estudos. Destaca-se, no testemunho de Yara, que as dificuldades pessoais, com estudo e trabalho, quase fizeram com que desistisse do curso, mas, mesmo assim, permaneceu estudando. Dessa maneira, viu-se que o trabalho influencia a trajetória desses estudantes indígenas nas universidades.

Essa etapa dos testemunhos trouxe à tona as compreensões, expectativas e os dilemas relativos à trajetória dos estudantes indígenas participantes da pesquisa nas universidades. Os aspectos que apareceram referem-se ao elemento motivador da opção pelo curso de administração e às motivações que os fazem permanecer nesse curso. Por fim, deram início ao diálogo sobre as expectativas e trajetórias sobre o mundo do trabalho.

\section{Trajetórias e expectativas sobre o mundo do trabalho}

Nessa temática dos testemunhos, a primeira constatação diz respeito às expectativas de se tornarem administradores aptos a concorrer a um emprego público, um interesse de muitos brasileiros, indígenas ou não, principalmente pela possibilidade de um emprego com estabilidade, o que pode significar uma concorrência de igual para igual com outros graduados não indígenas. Além disso, a possibilidade de administradores indígenas estarem vinculados a órgãos do poder público, do Estado brasileiro, como já mencionam Amaral, Rodrigues e Bilar (2014), pode elevar os interesses desses povos pela administração pública. Os autores citados analisam os interesses dos profissionais indígenas egressos das universidades estaduais do Paraná na atuação em gestão de organismos públicos importantes para as terras indígenas, como os da área da saúde e da educação, podendo vir a significar mudanças estruturais ainda não vistas, passando a ser "protagonistas da história e não mais tutelados" (AMARAL, RODRIGUES e BILAR, 2014, p. 135).

Constatou-se, ainda, o interesse desses estudantes em abrir um negócio ou uma empresa próxima às terras indígenas. A palavras negócio apareceu em todos os testemunhos e o motivo pode estar ligado a uma característica da orientação formativa do curso de administração, sendo uma possível peculiaridade de um pertencimento acadêmico nessa área de formação. Particularmente, o estudante Raoni evidenciou a necessidade de se superar o paternalismo e a tutela que historicamente os indígenas, afirmando que é preciso conquistar seu espaço e não ser tutelado, sendo essa uma possível influência da visão meritocrática que o curso tanto ensina. Pode ser que essa manifestação seja resultado do que aprendeu no curso e de que devam ser assim as relações das pessoas frente às oportunidades, mas também pode se referir à perspectiva de autonomia (e não tutela) perseguida historicamente pelos povos indígenas no Brasil.

Percebeu-se a existência de expectativas familiares particulares com relação à formação desses postulantes enquanto administradores, como a de "ganhar bem", no caso de Ubirajara, ou ter uma "profissão boa", como disse Yara. No que diz respeito ao retorno do conhecimento adquirido e socializado no curso de administração, para alguns deles, o ganho é profissional e pode ajudar em questões pessoais e familiares. Os entrevistados não evidenciaram com clareza como poderão articular os conhecimentos científicos e profissionais apreendidos com os conhecimentos tradicionais próprios de seus grupos étnicos e de suas comunidades, ainda que estejam presentes as diferenças e as tensões epistemológicas.

De qualquer forma, foi declarado que seria positiva a utilização de muito do que estão aprendendo no curso dentro da aldeia - por exemplo, quando Raoni diz que "administração pública na aldeia [...] seria fundamental". Ubirajara entende que o conhecimento adquirido na administração também poderia ser utilizado em benefício das aldeias, principalmente para cuidar de projetos. No entanto, ele relata: "seria uma boa para nós podermos investir nisso aí. Mas não dá, muita briga lá, não dá certo". Ubirajara mostra sua visão sobre os conflitos internos existentes em sua terra indígena e as consequências na aplicação de novos conhecimentos, bem como sua legitimidade para isso enquanto membro da comunidade.

Raoni e Ubirajara citam a necessidade de conhecimentos sobre administração pública e gestão de projetos como competências aprendidas no curso que podem ser utilizadas nas terras indígenas. Tudo isso retoma o que foi apresentado por Bajada e Trayler (2014) e Cassandre, Amaral e Silva (2016) com relação à importância da emergência da profissão de administrador em terras indígenas. Entretanto, assim como em comunidades e grupos não indígenas, foi relatado que, nas terras indígenas, há conflitos internos e faccionalismos entre grupos familiares que podem impedir a atuação desses novos profissionais ou reduzir a utilização desses conhecimentos. Tal situação pode ocorrer quando um cacique define a ocupação dos postos de trabalho na aldeia e não considera a importância dos graduandos e graduados em administração, muitas vezes por não compreender o significado e o papel desse profissional. Tal incompreensão também pode se manifestar quando os cursos de administração 
também desconhecem as realidades dos povos indígenas e suas ansiedades e necessidades, desconsiderando a atuação de profissionais indígenas nesses espaços.

Quando questionados se existe relação entre os conhecimentos aprendidos na universidade e os conhecimentos indígenas, houve unanimidade entre os entrevistados: todos entendem que são diferentes. Os conhecimentos indígenas foram relacionados à tradição indígena, aos costumes, à cultura e às regras de convivência da aldeia, "a raiz da gente", como disse Ubirajara. Já os conhecimentos aprendidos na universidade foram vinculados à profissão e ao crescimento pessoal.

Ainda com relação aos tipos de conhecimento, quando perguntados se o conceito de liderança é diferente para comunidades indígenas e não indígenas, observou-se, nos testemunhos, que liderança na terra indígena se liga a questões culturais, ao dinamismo da vida na aldeia e à hierarquia das decisões nesse território. Fora desse contexto, foram feitas relações com os órgãos governamentais e organizações empresariais. Por exemplo, na perspectiva de Ubirajara, líder não indígena é a pessoa que comanda uma empresa e, na de Niara, esse tipo de liderança não se aprofunda nas relações das pessoas. Raoni diz em seu testemunho que seu avô, tio e pai eram lideranças tradicionais em sua aldeia, uma descendência de lideranças políticas importantes no estado, e que a universidade pode contribuir para refletir e fortalecer sua memória de liderança ou apagar e ocultar isso, de acordo com os conceitos de lideranças (empresarial, gerencial) que disputam a formação do administrador.

Nas relações laborais, Niara e Raoni demonstraram um sentimento de que os não indígenas os olham, na profissão, com um pouco de receio, ou seja, suspeitam de suas intenções e competência, como declarou Niara: "no trabalho, o administrador indígena, assim, encontra uma dificuldade se às vezes assim [...], num ambiente de trabalho que fosse trabalhar, as pessoas podem te olhar diferente (em comparação ao olhar para não indígena)". Raoni foi mais enfático ao afirmar: "eu acho que [...] a sociedade espera mais de você, por você ser diferente, por você ser índio, se espera um pouco mais, é como se eles falassem assim: 'eu quero ver o que sai daí'”.

Quanto à expectativa do que é (ou que será) ser um administrador indígena, Kaingang ou Guarani, para Ubirajara e Niara não há diferença em relação a um administrador não indígena. Raoni entende que é um representante de seu povo que "vai se destacar por persistência, por defender aquilo que acredita, seus valores e sua ética [...] eu quero fazer a diferença!". Yara demonstrou um sentimento de que "administrador Guarani é orgulho. Tem vários que não são indígenas que queriam estar aqui no meu lugar. Eu tive essa oportunidade, eu passei no vestibular indígena, vários queriam estar aqui, só que eu estou". Assim, todos mostram a expectativa do que é ser um administrador indígena.

As compreensões, expectativas e os dilemas dos estudantes indígenas do curso de administração foram representados nos testemunhos como previa o objetivo desta pesquisa. Notou-se, neste tópico, que os testemunhantes manifestaram suas concepções acerca das trajetórias nas universidades e trajetórias e expectativas sobre o mundo do trabalho, que permitiram a efetividade do presente estudo.

Os testemunhos apresentados representam as percepções de cada estudante indígena que participou livremente desse estudo. Em conjunto, essas percepções podem transmitir a ideia do quão diversos são os povos indígenas e, assim, ajudar a perceber questões até então desconhecidas para eles e para a área da administração.

\section{CONSIDERAÇÕES FINAIS}

As reflexões apresentadas neste artigo circunscreveram-se em torno do duplo pertencimento dos estudantes indígenas acadêmico e étnico-comunitário -, buscando compreender a existência de vivências simultâneas desses sujeitos entre a universidade e suas comunidades de pertencimento. Nesta pesquisa, a interpretação se foca no fenômeno relacionado aos percursos dos estudantes indígenas nos cursos de administração, relacionando-os de forma dialética, a todo momento, com as dimensões referentes ao cotidiano desses sujeitos e à questão macrossocial. Assim, o significado de duplo pertencimento, neste estudo, pode ser entendido com outra roupagem, se visto no sentido restrito: pertencimento étnico-comunitário e pertencimento ao curso de administração, simultaneamente.

Os testemunhos também indicaram a existência de anseios em aplicar nas terras indígenas os conhecimentos adquiridos na universidade, o que pode ser um paradoxo para a atual demanda da formação de administrador, se os currículos dos cursos de administração não forem devidamente contextualizados às realidades indígenas. Nesse sentido, este estudo contribui ao 
problematizar esse conflito da demanda de ensino e aprendizagem na administração e ao dar novos contornos a debates relacionados ao significado do curso, com a inclusão do indígena como interessado nessa formação.

A presença de estudantes indígenas nos cursos de administração pode representar uma afirmação com relação às lutas travadas ao longo dos anos pelos diferentes povos indígenas no Brasil e na América Latina. Eles carregam, em suas características pessoais, seus conhecimentos, seus históricos, sua cultura, podendo elevar e postular suas compreensões para a universidade e para o curso de administração. As compreensões, expectativas e dilemas vivenciados por eles com relação ao seu percurso formativo foram representados, nesta pesquisa, em seus testemunhos.

No que diz respeito à trajetória nas universidades, os estudantes indígenas expuseram dificuldades que eles enfrentam cotidianamente durante o ano letivo, algumas por limitações estruturais para estudo em suas comunidades, como falta de internet, ou mesmo a fragilidade na formação básica dos estudantes indígenas decorrente de seu percurso de escolarização, se comparada ao capital cultural ou à formação escolar de outros estudantes não indígenas. A timidez de Yara pode estar relacionada com a insuficiência de repertório na escolarização para acompanhar os debates e as tarefas no ambiente acadêmico, somada aos preconceitos existentes junto aos professores e colegas de turma. Isso pode transformar o percurso de duplo pertencimento em momentos de sofrimento, visto o sentimento de exclusão de seus pares na universidade. Eis uma necessidade a ser vislumbrada pelo corpo docente dos cursos de administração: a criação de espaços e momentos de aproximação, reflexão e interculturalidade com as epistemologias e as realidades indígenas, a fim de evitar momentos de constrangimento, como o relatado no testemunho de Yara.

Quanto às trajetórias e expectativas sobre o mundo do trabalho, os estudantes indígenas, como muitos outros estudantes brasileiros, necessitam trabalhar e estudar simultaneamente, tendo tempo reduzido para estudar em casa. Outro fator complicador para os estudantes indígenas é a questão de deslocamento e a distância entre universidade e as terras indígenas, e que, em todos os relatos, apareceu como dificuldade, principalmente se considerada a questão de esgotamento físico ao final de cada dia de estudo-trabalho. Além disso, observou-se que alguns deles possuem filhos e família constituída, o que exige ainda maior atenção.

Entre os dilemas evidenciados, destacamos a existência de expectativas pessoais e particulares - muitas vezes fomentadas pela orientação individualista e meritocrática dos cursos de administração - e a dimensão coletiva e comunitária dos povos e comunidades indígenas. Nesse sentido, evidencia-se uma questão que pode servir de inspiração para outros projetos de pesquisa: como será a inserção profissional dos novos administradores indígenas e qual será o retorno dos conhecimentos adquiridos para as comunidades indígenas, dado o sentido original que orienta essa formação? A constituição de novos circuitos de trabalho indígena, conforme analisa Amaral (2010), pode mudar lógicas e dinâmicas de organizações atuantes em terras indígenas, e mobilizar e reconfigurar relações de poder no interior das comunidades, com o protagonismo de administradores indígenas.

O que é ser um acadêmico de administração indígena? A pergunta do título deste artigo não pode ser respondida de forma linear, tendo em vista a complexidade das comunidades indígenas, das universidades e do próprio sujeito indígena, marcado por identidades e pertencimentos. Entretanto, constatou-se que ser acadêmico de administração indígena é estar em uma constante luta para afirmar-se e permanecer estudando, devido aos fatores estruturais das universidades, que não foram pensados e planejados para os povos indígenas. Além disso, é estar em embate com a própria cultura e a estrutura hierárquica das aldeias, que pode rejeitar o emprego de conhecimentos não indígenas, fundamentalmente da área de administração, em seus territórios, muitas vezes por desconhecerem essa área ou mesmo por considerarem irrelevante para o seu tradicional modo de ser e de se organizar.

Nesse sentido, entende-se que ser acadêmico indígena de administração demanda assumir uma ação mediadora apontando conhecimentos acadêmicos da área de administração que possam afirmar o protagonismo e a autonomia de suas comunidades de pertencimento e, ao mesmo tempo, apontar os saberes tradicionais indígenas fundamentais que possam ser conhecidos e apropriados pelos cursos de administração.

Por fim, deve-se afirmar que este artigo teve a intenção de possibilitar a livre manifestação de estudantes indígenas, futuros administradores. Teve também o objetivo de provocar a elaboração de novas pesquisas que possam ajudar as trajetórias de outros estudantes indígenas no curso de administração. 


\section{REFERÊNCIAS}

AMARAL, W. R. do. As trajetórias dos estudantes indígenas nas universidades estaduais do Paraná: sujeitos e pertencimentos. 2010. Tese (Doutorado em Educação) - Universidade Federal do Paraná, Curitiba, 2010.

AMARAL, W. R. do; RODRIGUES, M. A.; BILAR, J. A. B. Os circuitos de trabalho indígena: possibilidades e desafios para acadêmicos e profissionais Kaingang na gestão das políticas públicas. Mediações, Londrina, v. 19, n. 2, p. 129-145, jul./dez. 2014.

AMARAL, W. R. do; CASSANDRE, M. P.; PAULA, L. A. Eu, Luciane, da etnia Kaingang: o testemunho de uma assistente social indígena e seu duplo pertencimento. In: I CONGRESSO INTERNACIONAL DE POLÍTICA SOCIAL E SERVIÇO SOCIAL: DESAFIOS CONTEMPORÂNEOS, 1., 2015, Londrina. Anais... Londrina: [s.n.], 2015.

AMARAL, W. R. do; FRAGA, L.; RODRIGUES, I. C. Universidade para indígenas a experiência do Paraná. Rio de Janeiro: FLACSO, GEA; UERJ, LPP, 2016.

ANGNES, J. S.; FREITAS, M. F. Q. de; KLOZOVSKI, M. L.; COSTA, Z. da F.; ROCHA, C. M. A permanência e a conclusão no ensino superior: O que dizem os Índios da Universidade Estadual do Centro Oeste do Paraná (UNICENTRO) - Brasil. Arquivos Analíticos de Politicas Educativas, v. 25, n. 6, 2017.

BAJADA, C.; TRAYLER R. A fresh approach to indigenous business education. Australia: Emerald Group Publishing Limited, 2014.

BARTH, F. Grupos étnicos e suas fronteiras. Bergen, Oslo: Universitetsforlagets, 1969. In: POUTIGNAT, P.; STREIFF-FENART, J. Teorias da etnicidade. Seguido de grupos étnicos e suas fronteiras de Fredrik Barth. São Paulo: Fundação Editora da UNESP, 1998.

BERNAL, D. D.; BURCIAGA, R.; CARMONA, J. Chicana/Latina testimonios: mapping the methodological, pedagogical, and political. Equity \& Excellence in Education, v. 45, n. 3, p. 363-372, 2012.

BODKIN-ANDREWS, G. H.; O'ROURKE, V.; DILLON, A.; CRAVEN, R. G.; YEUNG, A. S. Engaging the disengaged?: a longitudinal analysis of the relations between Indigenous and non-Indigenous Australian students' academic self-concept and disengagement. Journal of Cognitive Education and Psychology, v. 11, n. 2, 2012.

BOUTON-LEWIS, G. M.; WILSS, L.; LEWIS, D. C. Changes in conceptions of learning for indigenous Australian university students. British Journal of Educational Psychology, v. 71, p. 327-341, 2001.

CAMACHO, T. A universidade pública no Brasil. Revista Mexicana de Sociologia, Santiago do Chile, v. 19, n. 1, p. 101-132, 2005.

CAPELO, M. R. C.; TOMMASINO, K. Conflitos e dilemas da juventude indígena no Paraná: escolarização e trabalho como acesso à modernidade. Cadernos CERU, São Paulo, n. 15, 2004.

CARDOSO DE OLIVEIRA, R. Caminhos da identidade: ensaios sobre etnicidade e multiculturalismo. São Paulo; Brasília: Editora da Unesp; Paralelo 15, 2006.

CARDOSO DE OLIVEIRA, R. Identidade, etnia e estrutura social São Paulo: Pioneira, 1976.

CARDOSO DE OLIVEIRA, R. O índio e o mundo dos brancos. Brasília: Editora da UnB, 1964.
CARVALHO, M. L. B. de. Das terras dos índios a índios sem terras. O Estado e os Guarany do Oco'y. Violência, silêncio e luta. 2013. 835p. Tese (Doutorado em Geografia) - Programa de Pós-Graduação em Geografia Humana, Departamento de Geografia da Faculdade de Filosofia, Letras e Ciências Humanas, Universidade de São Paulo, São Paulo, 2013.

CASSANDRE, M. P.; AMARAL, W. R.; SILVA, A. Eu, Alex, da etnia Guarani: o testemunho de um estudante indígena de administração e seu duplo pertencimento. Cadernos EBAPE.BR, Rio de Janeiro, v. 14, n. 4, out./dez. 2016.

CUNHA, L. A. A universidade crítica: o ensino superior na república populista. 3. ed. São Paulo: Editora da UNESP, 2007.

CUNHA, L. A. A universidade temporã. 2. ed. Rio de Janeiro: Francisco Alves, 1980.

ESTÁCIO, M. A. F.; ALMEIDA, D. A. R. Indigenous in the Universidade do Estado do Amazonas. Journal of Research in Special Educational Needs, v. 16, 2016.

LARKIN, S. Indigenous Perspectives Enriching Scholarship. Australia: Australian Social Work, 2011.

MATO, D. Educação superior e povos indígenas: experiências, estudos e debates na América Latina e em outras regiões do mundo. Revista de Estudos e Pesquisas sobre as Américas, Brasília, v. 12, n. 3, 2018.

MINOGUE, K. O conceito de universidade. Brasília: Editora da UnB, 1981.

NOVAK, M. S. J. Política de ação afirmativa: a inserção dos indígenas nas Universidades Públicas Paranaenses. Maringá, PR: UEM, 2007.

OLIVEIRA, A. L. de; LOURENÇO, C. D. da S.; CASTRO, C. C. de. Ensino de administração nos EUA e no Brasil: evidências de um ensino com problemas. In: ENCONTRO NACIONAL DA ASSOCIAÇAO NACIOAL DE PÓS-GRADUAÇÃO EM PESQUISA EM ADMINISTRAÇÃO, 37., 2013, Rio de Janeiro. Anais... Rio de Janeiro: EnANPAD, 2013.

PAULINO, M. M. Povos indígenas e ações afirmativas: o caso do Paraná. 2008. 168f. Dissertação (Mestrado em Educação) - Universidade Federal do Rio de Janeiro, Rio de Janeiro, 2008.

PACHECO DE OLIVEIRA, J.; FREIRE, C. A. da R. A presença indígena na formação do Brasil. Brasília: MEC/SECAD, LACED; Museu Nacional, 2006.

RAKENA, T. O.; AIRINI; BROWN, D. Success for all: eroding the culture of power in the one-to-one teaching and learning context. International Journal of Music Education, v. 34, n. 3, 2016.

USHER, K.; LINDSAY, D.; MACKAY, W. An innovative nurse education program in the Torres Strait Islands. Nurse Education Today, v. 25, n. 6,2005

USHER, K.; MILLER, M.; TURALE, S.; GOOLD, S. Meeting the challenges of recruitment and retention of Indigenous people into nursing: outcomes of the Indigenous Nurse Education Working Group. Collegian, v. 12, n. 3, 2005.

XERRI, E. G. Breve incursão à história das universidades. In: ALBECHE, D. L. (Org.). Universidade e sociedade: visões de um Brasil em construção. Caxias do Sul: Educs, 2012. 
Renan Carlos Klichowski

ORCID: https://orcid.org/0000-0003-1113-8614

Mestre em Administração pela Universidade Estadual de Maringá (UEM), Maringá - PR, Brasil. E-mail: renan.kli@outlook.com

Marcio Pascoal Cassandre

ORCID: https://orcid.org/0000-0001-9415-4315

Doutor em Administração pela Universidade Positivo com período sanduíche pela University of Helsinki; Professor adjunto no Programa de Pós-Graduação em Administração da Universidade Estadual de Maringá (PPA/UEM), Maringá - PR, Brasil. E-mail: mpcassandre@uem.br

Wagner Roberto do Amaral

ORCID: https://orcid.org/0000-0002-8555-5915

Doutor em Educação pela Universidade Federal do Paraná (UFPR); Professor adjunto no Programa de Pós-Graduação em Serviço Social e Política Social da Universidade Estadual de Londrina (UEL), Londrina - PR, Brasil. E-mail: wramaral2011@hotmail.com 